\title{
ŞIRKET PLANLAMA MODELLERI
}

\author{
A. Argun KARACABEY*
}

\section{GIRIS}

Her işletme için gelecek bir sorundur çünkü her işletme kurulduğu ilk günden itibaren süreklitił̧ini korumayı (sonsuza dek yaşamayı) amaç edinmiştir ve geleceğ in belirsizlił̆i bu amacın gerçekleştirilmesi karşısındaki en ónemli engeldir. Dił̆er yandan, işletmeierin finansal amaçlanıı gerçekleştirebilmeleri ancak kıt olan kaynakların optimal kullanımı ile mümkün olacaktır. Gerek gelecekle başa çıkmak, gerek kıt olan kaynakların alternatif olanaklar arasında optimal kullanımını sağlamak planlama fonksiyonu yardımıyla gerçekleştirilebilir. Kısacası, planlama faaliyeti işletmelerin devamlılıklanı sağlayabilmeleri, amàçlarını gerçekleştirebilmeleri ve/veya amaçlanna ulaşmadaki etkinliklerini ôlçebilmeleri açısından gerekli olan bir faaliyettir.

Planlama faaliyetinin kendisinden beklenen bu amaçlan gerçekleştirebilmesi ancak ve ancak planlann gerçek dünyayı başarıyla yansıtabilmesi ile mümkün olacakur. Planlann gerçek dünyayı yansıtabilmeleri, planlann esnek olmalanna ve bu sayede gerçek (dış) dünyada meydana gelen deģişimierin anında planlara uygulanabilmesine bağlıdır. Bu ise günümüzde sadece planlama faaliyetlerine bilgisayar desteği sağlanması ile mümkündür. Özellikle, günümüzde tamamen deł̧işen talep yapısı ile gün geçtikçe sertleşen ve karmaşıklaşan rekabet yapısını dikkate aldığımız zaman, el ile geliştirilen planlar yardımı ile gelecekte başa çıkmaya çalışmak imkansız hale gelmekte; bilgisayar destekli planlama faaliyetleri bir zonunluluk olmaktadır.

1960'lı yıllarda geliştrilmeye başlanan bilgisayar destekli planlama modelleri, ancak 1970'li yıllarda yaşanan enerji krizleri, resesyonlar ve yüksek enflasyon sonucu geniş kullanım alanı bulabilmiştir. ${ }^{1}$ Bir şirketin mevcut veya muhtemel faaliyetlerinin tümü ya da bir bölümünün, veya şirketin ekonomik çevresinin ya da her ikisinin birlikte

\footnotetext{
*A.Ü. Siyasal Bilgiler Fakültesi Araştırma Gơrevlisi

${ }^{1}$ Thomas H. Naylor, Corpórate Planning Models, Addison-Wesley Publishing Company. Inc., 1979. s. 1.
} 
bilgisayar destekli temsili olan² bilgisayar destekli planlama modelleri, yðnetime sağladığı esneklik yanında, modeli oluşuran varsayım ve değişkenlerin değiştirilmesi ile daha fazla sayıda alternatifin, daha kısa bir süre içerisinde deģerlendirilebilmesini sağlayacaktur.

Bilgisayar destekli planlama modellerini ụ̧̈ alt sınıfa ayırmak mümkündür. Bunlardan ilki, panlamada kullanılan deģişkenlerin (sauşlar, maliyetler vb.) tahmini deģerlerini belirlemek amacıyla geliştirilen "tahmin modelleri"; ikincisi, ozel belirli bir yeni çabayı deģerlendirmeyi kolaylaşturmaya yőnelik "proje modelleri" ve üçüncüsü de genel koordinasyonun sağlanmasına, şirket bütçelerinin geliştirilmesine ve şirketin planlamasına destek sağlayan "şirket planlama modelleridir".

Şirket planlama modelleri, bir şirketin finans, pazarlama ve üretim faaliyetleri arasındaki ilişkileri, bilgisayarda programlanmıs matematiksel ve mantıksal ilişki sistemleri yardımıyla açıklamaya çalışmaktadıllar. ${ }^{3}$ Bu modeller şirketin alt seviyedeki stüreçleriyle işbirliģi içinde bütün şirketi kapsarlar.

\section{STIRKET PLANLAMA MODELleRINiN KAPSAMI VE ALT SISTEMLERI}

Herhangi bir işletmede bir şirket planlama modelinin geliştirilebilmesi ancak o işletmede bazı alt sistemlerin tulunması ile olanaklıdır. Bu alt sistemleri en genel şekilleriyle aşağıdaki gibi sıralamak mümkündür: ${ }^{4}$

1. Planlama sistemi

2. Bilgi sistemi

3. Bilgisayar sistemi

4. Modelleme sistemi.

1. Planlama Sistemi: En geniş anlamıyla planlama, "belirli bir amaç veya amaçlara ulaşmak için çeşitli seçenek yolların belirlenmesi, bu yollardan en uygun olanının seçilmesi ve uygulanmasi" olarak tanımlanabilir.

Planlama faaliyeti bir süreçtir ve bu süreç çeşitli aşamalardan meydana gelmektedir: llk olärak problemin ortaya konması, ve gerçekleştirilmesi istenen amaçlann belirlenmesi gereklidir. Amaçlar açık, anlaşılabilir, ulaşılabilir ve ölçülebilir biçimde ifade edilmelidir. Amaçlarnn oblçülebilir bir şekilde ifade edilmesi, gerçekleşen sonuçlarnn planla karşılaşturilabilmesi açısından onemlidir. ${ }^{5}$ Alternatif yolların belirlenmesi, alternatiflerin değerlendirilmesi ve en uygun alternatifin seçilmesi ikinci aşamadır. Planlamadan sözedebilmek için birden fazla seçenek yolun olması gereklidir. Bu seçenek yollardan en uygun yol, bu yolun amacı gerçekleştirmeye uygunlugu ve fayda/maliyet

2Hammond, J. S., "Do's and Don'ts Of Computer Models For Planning", Harvard Business Review, Vol. 52, No. 2, 1974.

${ }^{3}$ T. H. Naylor, age, s. 1.

4J. C. Higgins, Computer Based Planning Systems, Edward Amold, 1985, s. 1.

${ }^{5}$ Halil Sarıaslan, Yatırım Projelerinin Hazırlanması ve Değerlendirilmesi, Turhan Kitabevi. 1990 , s. 5. 
kriterleri gøzőnüne alınarak seçilir ve uygulamaya konulur. Son aşamada ise uygulamadan alınan sonuçlar beklenen sonuçlarla karşılaşurilarak kontrol edilirler.

Bir çok şirket için herhangi bir deģişiklik, eğer farkedilebilirse, bir tehlike olarak kabul edilir ve çoğunlukla đeł̧işim, şirketin finansal yapısını (ठzellikłe kărını) etkileyene kadar tam olarak gőzlenemez. Ileriye dőnük şirketler ise, gelecekte ortaya çıkabilecek yeni durumlardaki fırsatları görebilirler ve yenilikçi ónlemler sayesinde orgütün amaçlannı gerşekleştirmesi şansına sahip olabilirler. Daha da onemlisi bu şirketler, kendi yararlarnna olacak şekilde bir deģişim yaratmaya çalışırlar. Sirkei planlama, bu disiplini uygulayan şirketleri ileriye donük şirketler haline getirir. 6

2. Bilgi Sistemi: Genel olarak bilgi (information), haberlerin, raporların genel adi olarak kullanılmaktadır; yani bir insandan bir insana veya gruba veya makineye, bir gruptan bir insana veya gruba veya makineye ve benzeri şekilde iletişime konu olan şey bilgidir. Alt derecede, temel, işlem sürecinden geçirilmemiş bilgiye ise "veri" denir.?

Işletme yönetiminin kararları, günlük olaylarla ilgili rutin, basit kararlar ile işletme için hayati önem taşıyan çok önemlị kararlar arasındaki büyük alanı kapsarlar. Her karar için değişik düzeyde ve de ģişik kạsama sahip bilgi gerekmektedir. Işletmenin her bölümü için, her düzeydeki karan için gereken bilgiyi sağlayabilmek için işletmelerin "Bilgi Sistemi"ne sahip olmaları gerekmektedir.

Yönetim bilgi sistemi (MIS) ise; orgüt içindeki her yöneticiye, kendi sorumluluk alanı içinde, karar alma, planlama ve kontrol faaliyetlerini gerçekleştirebilmek için ihtiyaç duyduğu bilgiyi sağlayan sistemdir. ${ }^{8}$

Işletmede ihtiyaç dưyulan bilgi, bilgi kaynağına gớre ủç alt bolüme aynlabilir?:

- dışsal bilgi,

- içsel bilgi, ve

- rekabetçi bilgi.

Bir işletme, gelişmiş, ihtiyaçlarını tatmin edecek bir bilgi sistemine sahip olmak istiyorsa bu üç kategorideki temel planlama bilgilerini içeren bir raporlama sistemine sahip olmalıdır.

3. Bilgisayar Sistemleri: Bütün bilgisayar sistemleri, hem bilgisayarın kendisini oluşturan fiziksel parçaları ve hem de, daha onemli olan bilgisayara ne yapılacağını dikte eden programlan kapsar. ${ }^{10} \mathrm{Bir}$ açıdan birbirleriyle tamamen farklı olan fakat bir diğer açıdan tamamen birbirlerine bağımlı olan bu elemanlardan fiziksel parçalar "DONANIM (Hardware)", ve programlar da "YAZILIM (Software)" adını alırlar.

\footnotetext{
${ }^{6}$ David E. Hussey, Introducing Corporate Planning, Pergamon Press, 1991. s. 2.

7J. C. Higgins, age, s. 8.

8 J. C. Higgins, age, s. 10.

${ }^{9}$ D. R. Daniel, "Management Information Crisis". Harvard Business Review, 1961.

${ }^{10}$ Colin Lewis, Managing With Micros, The Economist, 1986, s. 3.
} 
Yüksek hızda işlem yapabilen ve veri depolayan elektronik bir aygıt olan bilgisayar beş onemli birimden oluşmaktadır. Bu birimler: girdi, bellek, kontrol, aritmetik/mantık ve çıku birinleridir. ${ }^{11}$ Girdi ve çıkt birimleriyle ilgili bütün araçlarla (klavye, mouse, yazıcı, ekran vb.), hareketli ve sabit disklere "bilginin alındığı ve verildigi yerler (peripherals) '; geri kalan üç birime (bellek, kontrol, aritmetik/mantık birimleri) ise "Merkezi Işlern Birimi (Central Processing Unit-CPU)". denir. ${ }^{12}$

Bilgisayarlarnn istenilen amaca uygun olarak çalışmalarını sağlayan yazılım, bütün bilgisayar programlannı ifade edebilmek için kulanılan ortak bir isimdir. Bilgisayar programlan, belirli bir uygulama için bilgisayạ talimatlan sağlıyor olabilecekleri gibi (Uygulama Yazilımı - Applications Software); üst düzeyde bir bilgisayar dilini daha alt düzeyde bir bilgisayar diline çevirme, bilgisayar parçalanıın kendi aralarında ve onlarla CPU arasındaki bilgi akışını düzenleme ve genel olarak da bilgisayarın tüm işleyişini kontrol etme görevini gerçekleştiriyor olabilirler (Sistem Yazılımı - Systems Software) ${ }^{13}$. Uygulama yazılımı BASIC, Cobol, Pascal gibi bilgisayar programlama dillerini, Word, Professional Write gibi kelime işlemcileri, Lotus, Quatro gibi elektronik tablolama programlarını ve tenzeri paket programları içerirken; sistem yazılımı DOS ve UNIX gibi işletim sistemlerini içermektedir.

4. Modelleme Sistemi: En bilinen (temel) tanımıla model "gerçek sistemlerin temsilidir". Bu tanımda gerçek kavramı sadece şu anda mevcut sistemleri anlatmak için kullanılmaz, gılecekteki olası sistemleri de, içerir.

Inceleme konusu şu anda mevcut olan bir sistem ise, modelin amacı sistemin performansını geliştirmek çabası ile sistemin davranışlarını analiz etmektir. Inceleme konusu şu anda mevcut olmayan, ancak ileride mevcut olabilecek veya uygulamaya konulabilecek bir sistem ise, modelin amacı sistemin bileşenleri arasında fonksiyonel ilişkileri içeren sistemin ideal yapısını tanımlamakur. ${ }^{14}$

Modelin kullanıcıya sałlayacağı kolaylıklan şu şekilde sıralayabiliriz:

- modeller zamandan tasarruf sağlar.

- modeller kolayca anlaşıllır, ve

- gerekirse hemen düzeltilebilir.

Karar verme sürecini makineleştirme yolundaki çilim, model yoluyla problem çozümlemeyi yaygınlaş̧ırmakıadır. Modeller karardan elde edilecek sonuçların daha iyi gösterilmesini sağlar. Herhangi bir duruma ilişkin ana model kurulunca, deł̧işkenlerdeki değişiklikleri süratli bir şekilde göstermek mümkün olur. Ayrıca değişkenler arasında çeşitli bağınular kurulup sonuçlar çıkanlabilir. ${ }^{15}$

Işletme yơnetiminde bilgisayar kullanımı artıkça buna paralcl olarak bilgisayar programlannın temelini oluşturan matematiksel modellerin önemi de artmıştur.

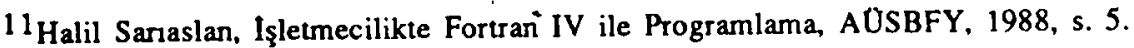

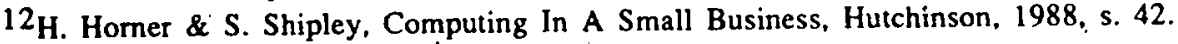

${ }^{13}$ Colin Lewis, age, s. 31-32.

14 Paul N. Finlay, Mathematical Modelling In Business Decision Making, Croom Hell, 1985 , s. 35 .

15Salim Şen, Ișletme Yönetımine Modeller Yoluyla Yaklaşım, AITIA, 1978, s. 26. 
Matematiksel modeller, bir veya daha fazla olayın geçmişte ve şimdikj zamanda elde edilmiş sonuçlarından yararlanarak bu olayın gelecekte ne gibi sonuçlar doğuracą̆ını veya birden fazla olay varsa, bu olayların geçmişteki sonuçlarını analiz edip onlar arasındaki ilişkileri kurarak karşılıklı etkileşmelerinin ilerideki oluşumlanna ne şekilde etkiler yapacağını araşırmamıza yardımcı olan kantitatif tekniklerdir. ${ }^{16}$

Temel olarak bir matematiksel model geliştirme süreci aşağıdaki aşamalardan meydana gelir. ${ }^{17}$

1. Problemi belirleme ve tanımlama

2. Deģiskenler ve sınırlamaların (kısıtlukklann) analizi

3. Değişkenler arası ilişkilerin tanımlanması

4. Formülasyon (Sembolleşirme)

5. Modelin geliştirilmesi

6. Modelin test edilmesi

7. Modelin uygulanması.

Model geliştirirken gozzetilen temel amaç, işletmenin karşılaşabileceği yeni durumlann yaratabileceği olası risk ve maliyetlere katlanmadan bunlan model üzerinde test etmektir. Bu amacı gerçekleştirebilmek için modellerin gerçekçi olması gereklidir ${ }^{18}$. Yani modelin ürettiği sonuçlanın, gerçek dünyada da beklenen sonuçlar olması gerekir, ancak bir model gerçek her durumu kapsarsa karmaşı olacak ve modele katulacak her bir yeni deģişken daha az avantaj są̧layacakır. Aynca modelin hatasız olarak geliş̧irilmesi de çok zor bir hale gelecektir. Dolayısıyla bir modelin gerçeği yansıtmak için sahip olması gereken karmaşıklık ve doğru geliştirilebilmesi için sahip olması gereken basitlik arasinda bir denge kurmak gerekecektir.

\section{III. ŞIRKET PLANLAMA MODELI GELIŞTIRME TEKNIKLERI}

Şirket planlama modeli geliş̧tirilirken kullanılan teknikler çeşitli şekillerde sınıflandınlabilmektedirler. Bazı kaynaklarda bu teknikler; (i) olasılık simulasyonu, (ii) belirli halde (deterministik) simulasyon, (iii) optimizasyon ve (iv) tahmin modelleri ${ }^{19}$ diye sınıflandırlırken, bazı-kaynaklarda ise (i) optimizasyon modelleri, (ii) ekonometrik modeller, (iii) sistem dinamikleri modelleri, (iv) simulasyon modelleri ${ }^{20}$ diye sınıflandırılmaktadır. Ancak en genel kabul görmüs şekliyle bunlan optimizasyon ve simulasyon modelleri olarak iki alt grupta ele almak mümkündür.

Simulasyon modelleri yönetimin kontrolü altındaki durumlann ve çevre ile ilgili varsayımların değerlendirilmesi sonucunda gelecek planlarının etkilerinin test

${ }^{16}$ Erol Eren, 1şletmelerde Stratejik Planlama. Yönetim ve Organizyon Enstitüsu. 1979, s. 208.

${ }^{17}$ David Asch \& G. Roland Kaye. Financial Planning: Modelling Methods And Techniques, Kogan Page, 1989, s. 173.

18 D. Asch \& G.R. Kaye, age, s. 18

$19 \mathrm{~J}$. C. Higgins, age, s. 163.

${ }^{20}$ R. Kumar \& P. Vrat, "Using Computer Models In Corporate Planning", Long Range Planning, Vol. 22, No. 2, 1989, s. 116. 
edilebilmesini sağlarken; optimizasyon modelleri kontrol edilebilir deģişkenleri uyarlayarak en iyi planı aramiayı sağlarlar. ${ }^{21}$

Işletme problemlerinin analizi için tanımlanan bir sistemin modeli bazan çok karmaşık olabileceģi gibi kurulan modeli analitik veya sayısal olarak çözmek de gụ̧̈ olabilir. Bu durumlarda simulasyon onemli bir model kurma ve çozme teknigi olarak kullanilur 22 .

Olasılık simulasyon yisntemi, olasilıklı ve çðzüm için kesin bir formülün bulunmadığı problemleri çözın’k için başvurulan ve gerçek evreni (ana külleyi) andıran kuramsal ơmekler kullanarak çözüme ulaşmaya çalışan ve genellikle "Monte Carlo" adı ile bilinen yơntemdir ${ }^{23}$. Bu yơntem basit olarak, bilgisayann her veri değişken (input variable) için uygun hesaplamaların yapılması amacıyla, rastgele olasılık sayılara dayalı olarak bir değer seçmesini içerir ${ }^{24}$.

Bir diğer simulasyon yőntemi belirli halde (deterministik) simulasyondur. Bu yöntem "sistem benzetimi" yőntemi olarak da adlandırılır. Bu yöntem gerçek sistemi temsil eden bir model üzerinde gerçek verileri kullanarak sistemin işleyişi konusunda bilgi edinilmesini sağlar. Monte Carlo ile bu yontem arasındaki en belirgin fark, birincisinin ormek ve verileri gerçek sistem yerine gerçek sistemi andıran bir kuramsal modelden almasıdrr. Fakat deterministik simulasyon yöntemi gerçek sistemin modelini kullanır, ómekleri gerçek modelden seçer ve gerçek verileri işler. Ikinci bir fark ise deterministik simulasyon yớnteminde kullanılan model analitik olarak çözümlenebilir ${ }^{25}$.

Şirket planlama modellerinin geliş̧irilmesinde kullanılan bir diğer onemli teknik ise optimizasyon modelleridir. Işletme yőneticileri, şirket modellerini seçenek senaryolarinın belirlenmesinıle harcanan zaman ve çabadan tasarruf sağladıklan ve çok fazla seçenȩ̧in değerlendirilmesine imkan verdikleri için kullanırlar. Seçilen senaryonun diger seçenek senaryolardan farklılı̈ı genellikle ürün fiyatı veya satış tahminleri gibi alt düzey değişkenler açısından olmakta; yönetimin dikkate alması gereken temettü oranlan veya likidite oranlan gibi üst dizzey değişkenler çoğu modelde gözardı edilmcktedirler ${ }^{26}$. Optimizasyon modelleri büyük ölçüde bu aksaklığı gidermek amacını gütmektedirler. Bir optimizasyon modelinde, geneilikle yüksek seviyeli deģişkenler kullanılarak ifade edilen şirket politikalan modele kısıtlılık olarak verilir, ve bu koşullan sağlayan en iyi senaryo bulunmaya çalışılır.

Pratikte optimizasyon nodelleri matematiksel programlama tekniģinin herhangi bir yơntemine dayandınlmaktadır ve bunlar arasında en bilineni ve en geniş kullanıma sahip olanı "Doğrusal Programlama"dır. Dogrusal programlama problemi

21 J. S. Hammond, agm.

22 Osman Halaç, Kantitatif Karar Verme Teknikleri, Arpaz Matbaacılık, 1978, s. 443.

${ }^{23}$ Halil Sarıaslan. Sıra Bekleme Sistemlerinde Simulasyon Teknił̧i, A. O. Siyasal Bilgilet Fakultesi Yayınlan, 1989, s. 38.

$24 \mathrm{~J}$. C. Higgins, age, s. 164.

25 Halil Sariaslan, age, s. 38.

26J. W. Bryant, "Concepl. And Techniques Of Financial Modelling", Financial Modclling In Corporate Management, Edited By J. W. Bryant, John Wiley \& Sons, 1987, s. 22. 
gerçekleştirilmesi arzu edilen, açık ve olçuluebilir bir biçimde belirlenen bir doğrusal amaç fonksiyonu ile bu amaç fonksiyonunun gerçekleşme derecesini yani alabileceği sayısal deģerleri sunırlayan, doģrusal eşitlik ve eşitsizlikler biçiminde ifade edilen kısıtlılıklardan oluşur. ${ }^{27}$ Optimizasyon amacıyla kullanılan diğer yơntemlerden bazılan ise, kuadratik programlama, tam sayll programlama ve dinamik programlamadir.

Uygulamada ise deterministik simulasyon modellerinin geniş kullanım olanağı bulduơ̆u sőylenebilir. Yapılan bir araşurmanm sonuçlanna göre, ele alınan 65 şirket içerisinde sadece 14 şirket optimizasyon modelleri kullanmakta ve bu 14 şirketin 13 tanesi aynı zamanda simulasyon modellerini de kullanmaktadur. Yani sadece optimizasyon modeli kullanan şirket sayısı birdir 28 .

Deterministik simulasyon modellerine yőneltilen en onemli eleştiri şu şekildedir: Bu modeller yơneticiye onemli kararlan almada çok az yardımcı olmakta ve işin çoğu modelden bağımsız olarak yaturım ve finansman kararlan arasındaki ilişkileri kuran yőnetici tarafından yapılmaktadır. Bu modellerin asıl yararlan, veri işleme sürecini hizlandirmalandir 29 .

Gerçekte, simulasyon modellerinin daha fazla kullanılmalannın nedeni, optimizasyon modellerinin başan oranlarının düşüklügüu ve yơneticilerin simulasyon modellerinin daha rahat anlaşılabilir olduğunu ve karmaşı ilişkilerin simulasyon modellerinde optimizasyon modellerine nispetle daha kolay temsil edildiğini düşünmeleridir.

Optimizasyon modellerinin başarısızlığının en onemli nedeni, bu modelleri kullanan yơneticinin bu modellerin en onemli kararlarda bile kendisini gozardı ettigini duş̧ümesidir. Yơneticiyi bu sekilde düşünmeye yơnelten şey, bu modellerin optimal bir çözüm ararken birçok kısıthlığı eşanlı olarak dikkate almalandır. Yơnetici ise sonunlan eşanlı olarak düşünmediợi için kendi dúş̧ünce!erinden yola çıkılarak geliş̧irilen model ve içindeki ilişkileri anlamasına rał̆men, kendisini dışlanmıs hissetmektedir ${ }^{30}$.

Kısacası optimizasyon modellerinin en üstün yanı olan birden fazla karar seçeneğini ve kısıtlıı̆̆ını eşanlı olarak gőzönüne alması, yơneticilerin bu modelleri kabullenmesini zorlaşurmakta, dolayısıyla simulasyon (ozellikle deterministik simulasyon) modelleri daha yaygın kullanım olanağı bulmaktadırlar.

\section{SIRKET PLANLAMA MODELI GELIŞTIRME SŨRECI}

Daha once de belirtildiği gibi, şirket planiama alanındaki gelişmelerin en onemlisi, şirket planlama için geliştirilen bilgisayar destekli modeller olmuştur. Bu modeller planlamacılara, geleneksel planlama yöntemlerinin mümkün kıldığından daha

${ }^{27}$ Halil Sarıaslan, Kaynak Dağılımında Dogrrusal Programlama, Turhan Kirabevi, 1990, s. 56.

28 J. C. Higgins, age, s. 165 .

29 John Holland. "A Methodological Account Of Financial Modelling". Financial Modelling In Corporate Management, Edited By J. W. Bryant, 1987, s. 138.

30 John Holland, age, s. 139. 
fazla sayıda alternatifi daha kapsamlı olarak planlama kapsamına alma firsatı tanımışưr ${ }^{31}$.

Sağladığı bu kolaylıktan ve gerek donanım gerek yazılım teknolojilerindeki ilerlemelerden dolayı kıllanım alanı genişleyen şirket planlama modellerinin örgütler tarafından kabul edilmeleri, bir cok şirketin planlama modeli geliştirme ve uygulamadan sorumlu şirket planlanıa bólümleri kurmalarıyla sonuçlanmışırı. Şirket planlama bỏlümü, alt birimlerin raporlarında kullanacakları sekli belirledikten sonra, alt birimler hazırladıklan planlan şirket planlama bolümüne konsolidasyon, düzeltmeler ve deģerlendirmeler için yollarlar. Bu planlar, belirlenen şirket amaçlan doğrultusunda tekrar düzenlenmek için alt birimlere geri yollanırlar, ve bu sürę̧ bütün birimlerin planlan uygun görülüp, konsolide edilene kadar devam eder ${ }^{32}$.

En geniş anlamıyla, bir şirket planlama modeli geliştirme süreci, aşă̆ıda ozetlenen on aşama altunda toplanabilir.

1. Ilk olarak yapılması gereken şey hangi süreçler için bir model geliştirmenin yararh olacăğının belirlenmesidir ${ }^{33}$. Bir şirket planlama modeli, temel olarak ü̧̧ ana süreci kapsamalı; bu dị̣ sürecin planlarının konsolidasyonu sonucunda şirket planlama modeli elde edilmelidir. Bu úç temel sürec, pazarlama, üretim ve finansmandur.

Hangi süreçler için model geliştirmenin yararh olacağını belirleyebilmek için şirketin planlama faahiyetleri yeniden gőzden geçirilmelidir. Bu gözden geçirme faaliyetinin, şirket dışından biri tarafından gerçekleştirilmesi bu faaliyetin objektif olmasını są̧layacakur. Bu faaliyet; (i) ơrgüt yapısının, (ii) yőnetim felsefesi ve stilinin, (iii) şirketin çevresinin, (iv) planlama sürecinin analizi ve yeniden degerlendirilmesini kapsamalıdır ${ }^{34}$.

2. Şirketin planlama intiyaçlanı belirlenmelidir. Bu aşamada şirketin planlama ihtiyaçlan, bólümlerin planlama ihtiyaçları, planlama için gereken veriler, planlama dőneminin temel stratcjileri belirlendikten sonra, şirket yönetimi seçenek yöntemlerin neler olduğu sorusuna cevap arayacakur. Bu aşamada, doğal olarak, bir model geliştirilip geliştirilmeyeceği konusunda da bir karar verilecektir. Şirket için en uygun olan yöntemin seçilmesindı cevaplandırılması gereken üç önemli soru şunlardır: yöntem; teknik olarak olabilir midir, ekonomik olarak olabilir midir, ve örgüt bu yöntemi kabul edip uygulayacak midur?

3. Üçüncỉ aşamada yapılacak olan şey modelden beklenen ozelliklerin belirlenmesidir. Model geliştirilmesinde yönetimin amacı, temel girdi ve çıktıların neler olacağı, modelin yapisı ve modelin nasıl kullanılacağı belirlenir. Model kullanıcıya hangi faaliyetinde destek sał̧layacakur, bu desteği gerektiơi gibi sağlayabilmesi için model ne tür bilgiler üretmelidir ve bu bilgilerin üretilebilmesi için modele hangi veriler girilmelidir gibi soruların cevapları bu aşamada belirlenecektir.

31 W. F. Hamilton \& M. A. Moses, "A Computer Based Planning System". Managemet Science, Vol 21, No. 2, 1974.

32T. H. Naylor, age, s. 16-17.

$33 \mathrm{~J}$. S. Hammond, age, s. 17.

${ }^{34}$ T. H. Naylor, age, s. 4647 . 
4. Modelin sahip olması istenilen ozellikler belirlendikten sonra model için bir taslak hazırlanır. Bu taslak yardımıyla modelin faydalan ve maliyetleri açıkça ortaya konularak, model geliştirilip geliştirilmeyeceği hakkında kesin bir karar verilir. Model geliştirilmesine karar verilince, oncelikle şirketin mevcut planlama sisteminin kaynaklan incelenir; bir onceki aşamada belirlenen model geliştirmek için gereken kaynaklar ile bunlar karşılaşurılır. Bu aşamada son olarak yapılacak olan șey, model geliştirilmesi işini yürütecek olan kişiyi belirlemek olacaktur.

5. Modelin ozellikleri, yapısı ve modelci belirlendikten sonra artuk modelin geliştirilmesine başlanabilir. Model geliştirilirken aynı anda veri toplama işlemi de gerçekleştirilmelidir. Bu aşamada sơzkonusu olan model geliştirme süreci daha once ele alınan matematiksel model geliştirme süreci ile bu modelin bilgisayar diliyle ifadesinden meydana gelmektedir.

6. Model test edilerek, hatalan giderilir. Amaç modelin istenileni gerçekleştirip gerçekleştirmediģini belirlemektir. Bunun için ilk olarak modelde yer alan ilişkilerin mantığı, yani ilişkilerin gerçek hayattaki ilişkileri yansıtıp yansıtamadıkları belirlenmelidir. Ilişkilerin manuğ ${ }_{1}$ doğrulandıktan sonra, bu ilişkilerin bilgisayar diliyle ifadeleri dogrulanmalidir.

7. Model dogrulandıktan sonra modeli kullanacaklar eğitilmelidir. Bu eğitim hem modelin etkin kullanımını hem de kullanıcılar tarafından modelin kabul edilmesini sağlayacakur.

8. Eğitimi tamamlanan kullanıciların modeli test etmeleri gereklidir. Burada test edilen şey modelin manuğıı veya modelin doğru çalışıp çalışmadığı değil, modelin ürettiği çıkulann kullanıcılanı karar almasına yardımcı olup olamayacą̧ıdır.

9. Bu aşamada model kullanıma sokulacakur. Ancak, planlama modeliyle planlama süreci başarnlı. bir şekilde birleştirilemezse, modelin kullanım alanı oldukça sinırlı olacakır. Bu birleştirmenin başarılı olabilmesi için gerekirse planlama süreci baştan dizayn edilmelidir.

10. Son aşama olarak, uygulamaya konulan model izlenmeli; modelden alınan çıktıların modelin amacını gerçekleştirip gerçekleştirmediği belirlenmeli ve buna gore model gozden geçirilmeli ve gerekiyorsa yeniden model geliştirme aşamalan tekrar edilmelidir.

Etkili, başarılı bir şirket planlama modeli geliştirebilmek için bu aşamalar arasında ekkin bir geribildirim mekanizmasının çalışurilması bir zorunluluktur ${ }^{35}$.

\section{GENEL DEGERLENDIRME VE SONUÇ}

Işletmelerde bilgisayar kullanımının bilgisayar teknolojisindeki gelişmelere paralel olarak gelişmesiyle birlikte bir zamanlar sadece günlük rutin işlerin gerçckleştrilmesinde kullanılan bilgisayarlar, stratejik konularda alınacak kararlarda da kullanılmaya

35 J. C. Higgins, age, s. 160 . 
başlanmışur. Bu gelişinnin bir ơmeği olan bilgisayar destekli planlama modellerinin, şirket planlama amacıy |a kıllianılan bir çeșidi olan Şirket Planlama Modelleri, çok kısa bir süre içerisinde kullauucınıı çeşitli senaryolann ve varsayımlann sonuçlanıı bu model üzerinde denemesine fusat vermesi, gerçek dünyada meydana gelen değişmelerin anında modele yansitulmasına olanak tanıması ile işletmelerin planlama fonksiyonunda vazgeçilmez bir yere sahip oimuşlardir.

Güümüzde şirket planlama modellerini kullanan şirketlerin sayısı her geçen gün artmakla birlikte, bu siłyı tralen toplam şirketler içinde çok küçük bir orandır. Bunun boyle olmasının en onemli nexleni bu modellerin geçmişlerinde pek şok başansızlığa ve hayalkunklıgına neden cimuş olmalandir.

Bu modellerin loaşansız olmalarının pek çok, değişik nedeni bulunabilir. Bu nedenlerden ilki ve belki de en onemlilerinden birisi modelin çठzmesi beklenen problemin yanlıs tanımlanmasıdır.

Bir kere probleın tanınlandıktan sonra yapılan şeylerin çoğu bir takım teknik ayrıntılardan ibarettir. Problemin yanlış tanımlanması modelin geçerliliğini kaybetmesinin yanısıra, kit kaynakdarn bos yere harcanmalan sonucunu da doguracaktr.

Bir diğer onemli neden ise tatmin edilmeyen beklentilerdir. Bir çok modelci yơnetimin güvenini kazanabilmek amacıyla geliştirecekleri modellerin ozelliklerini abartarak yőnetime aklanrlar. Yönetimin modele güven duyması iyi olmakla birlikte, yơnetimin modelden baklentilerinin gerçeği yansıtmaktan uzak bir şekilde gelişmesi ise modelin uygulamaya konulduğu zaman kendisinden beklenenleri gerçekleştirememesine neden olacakur. Modellerin basansızliklaranın bir nedeni de yetersiz belgelemedir. Bir model sozzkonusu olduj̧̧u zaman üç tip belgeleme çalışması gerçekleşmelidir. Bunlardan ilki yơnetime modelin kullanımı hakkında bilgi vermek için gerçekleştrilecek belgeleme sistemidir. Buradaki belgeler teknik ayrıntulara girmeden, yơnetimin rahatça anlayabileceģi bir dilde yai:ılmıs olmalıdır. Ikinci tip belgeleme sistemi modelin kullanıcısına yőnelik bir sistemdir. Bu sistem modelin kullanımında ki sürekliliği sağlamak açısından çolk onememlidir. Herhangi bir nedenle modelin kullanıcısı değiştiğinde yeni kullanıcının modeli kullanmasını sał̆layabilmek onceden yapılan çalış̧alann belgelerinin bulunup bulunmamasina bağlıđ̆r. Üçüncü olarak, teknik belgeler ileride modelde gerçekleştirilecek de ģişimlerin sağlanabilmesi için gereklidirler.

Yơnetimin modele desteğini sağlayabilmek, modelin geçerliliği açısından en onemli etkenlerden bir tanesidir. Bunun için modelcinin yapacağı çalışmalarda, yőnetimin rahatça anlayabileceğ $\mathrm{i}$, teknik terimlere çok fazla yer vermeyen bir dil kullanmaması yơnetimin bu çalışmalarra soğguk kalmasına neden olacakur.

Modellerin başıınsız: olmalanna neden olan bir başka etken ise modellerin gerekli verileri saglayacak bir bilgi sistemi veya veri labanıyla desteklenmemeleridir.

Bu nedenlerden ba:ka, modelin yararli sonuçlar üretememesi, modelin tek bir problemi çőzümlemeye yönelik geliştirilmessi, modelin tek bir kişiye bağımlı olarak geliştirilmesi, yeterli politik desteğin olmaması, fayda/maliyet analizlerinin hatalı yapilması ve benzeri faktorlerde modellerin başansız olmalanna neden olmaktadırlar. 
Bu yanlışlann sorumluluğu yơnetime, modelciye veya kullanıcılara yüklenebilir. Bu yanlışlan engellemek için dikkat edilmesi gereken bazı temel noktalar vardır. Bunlann bazılan şu şekildedir.

- Ilk olarak modellere yơnetimin desteği gereklidir. Bu destek model gelişirme çabasının başlangıcından, modelin kullanıma sokulması safhasının sonuna kadar gereklidir. Eģer yơnetimin modellere desteğ $i$ ve inancı sağlanamazsa, bir modelin başanlı olmasını beklemek imkansızdır. Geçmişte yapılan bir çok araşırma gőstermiştir ki, modellerin çoğu bizzat yőnetim tarafından kullanılmaktadır. Dolayısıyla, herşey bir yana modelin kullanıma sokulması bile direkt olarak yonetimin modeli kabullenip kabullenmemesiyle iliş̧ilidir. Her yőneticinin, geçmiş deneyimlerine uygun olarak kendi kafasında belirli bir düşünce biçimi ve rapor format oluşmuştur, ve modelin ürettiği çıktıların bu kalıplara uygun olması modelin başarı şansını arturacaktır.

- Modelin amaçlan açıkça belirlenmelidir. Başanyla geliştirilen birçok model, amaçiarın yanlış belirlenmesi nedeniyle kullanılmamışlardır. Amaçlar, bir anlamda modelden beklenenlerin ifadesidir; ve ę̧er bunlar açıklıkla belirtilmemişse, model yönetimin ihtiyaçlanını tatminden uzak olacakur.

- Modelci, her şeyden önce modellemeye konu olan faaliyetleri iyi anlamalıdır ki; buradaki ilişkileri matematiksel olarak ifade edebilsin. Modelci, kendisine yonetim tarafından verilen bilgilerle yetinmeyip, kendisi ơrgütü ve modellemeye konu olan alanı anlamaya çalışmalıdır.

- Modelci, modelin çalışması için gereken verilerin mevcut olduğundan ve bu verilerin elde edilebilecełinden emin olmalıdır.

- Geliştirilen ilk model mümkün olduğunca basit olmalıdir. Basit bir modelin geliştirilmesi bir çok hatanın önlenmesinin yanında, yönetimin modeli kabul etmesini kolaylaştıracakur. Şirket, modelleme konusunda deneyim kazandıkça, büyük bir tek model yerine, bir ką̧ tane daha kü̧̧ük model geliştirmesi daha iyi olacakur. Ancak basit bir model kuracağım diye ơnemli bazı ilişkilerin modelin dışında bırakılması daha büyük bir hatadur.

- Model esnek olmalıdır. Esneklik iki şekilde sınıflandınlabilir: manuk esnekligi ve yapısal esneklik. Modeideki esnek mantık sayesinde yeniden programlamaya gerek kalmadan model çerçevesinde meydana gelen deģişimlere uyum sağlayabilecektir. Yapısal esneklik ise, ózellikle bir ką̧ modelin olduğu durumlarda kullanıcının bu modelleri istediģi sırada kullanabilmesini sał̆layacakur.

- Modelin potansiyel kullanıcılan, model geliştirme sürecine dahil edilirlerse hem modelin mantıgını daha iyi kavrayacaklardır, hem de modelin etkin bir biçimde nasıl kullanılacağını ögreneceklerdir.

Bu noktalara dikkat edilerek geliştirilen bir modelin başarılı olmaması için bir neden yoktur.

Bilgisayar destekli bir model yardımıyla yapılan her türlü işlemin el ile de yapılması mümkündür; ancak bilgisayann hızı ve işlemlerde ki doğruluğu modelin daha 
geniş bir varsayımlar seti ve daha karmaşık matematiksel işlemler ile çalışabilmesini ve yönetime dif̧er stratejik konulara daha fazla zamạn ayuma imkanı sałlar.

Sonuç olarak diyebiliriz kj; ülkemizde üzerinde henüz fazla durulmayan bu planlama teknił̆inin, ozellikle belirsizliklerin çok. fazla olduğu koşullar alunda işletme yonetimine yardımcı olabilme kabiliyeti gőzónüne alınırsa, küreselleşme ve bunun yaratuğ 1 keskin rekabet ortamı, bilgi teknolojisinde ki gelişmeler ve bunun sonucunda oluşan esnek talep yapısı ve benzeri gelişmeler sonucu artan belirsizlik ortamında bu tekniğin Türk işletmeleri için bir zorunluluk haline geleceğini soylemek mümkündür.

\section{KAYNAKÇA}

Asch, David \& Kaye, G. Foland, Financial Planning: Modelling Methods And Techniques, Kogan Page, 1989.

Bryant, J. W., (Edited By), Financial Modelling In Corporate Management, John Wiley \& Sons, 1987.

Daniel, D. R., "Management Information Crisis", Harvard Business Review, 1961.

Eren, Erol, Işletmelerde Stratejik Planlama, Yőnetim ve Organiźasyon Enstitüsü, 1979.

Finlay, Paul, N., Mathematical Modelling In Business Decision Making, Croom Hell, 1985.

Halaç, Osman, Kantitatif Karar Verme Teknikleri, Arpaz Matbaacilık, 1978.

Hamilton, W. F. \& Moses, M. A., "A Computer Based Planning System", Management Science, Vol. 21, No. 2, 1974.

Hammond, J. S., "Do's And Don'ts Of Computer Models For Planning", Harvard Business Review, Vol. 52, No. 2, 1974.

Higgins, J. C., Computer Based Planning Systems, Edward Amold, 1985.

Homer, H. \& Shipley, S.,Computing In A Small Business, Hutchinson, 1988.

Hussey, David E., Introducing Corporate Planning, Pergamon Press, 1991.

Kumar, R. \& Vrat, P., "Using Computer Models In Corporate Planning", Long Range Planning, Vol. 22, No. 2, 1989.

Lewis, Colin, Managing With Micros, The Economist, 1986.

Naylor, Thomas H., Coprorate Planning Models, Addison-Wesley Publishing Company, Inc., 1979. 
Sarıaslan, Haliı, Yatırım Projelerinin Hazırlanması ve Değerlendirilmesi, Turhan Kitabevi, 1990.

Sarłaslan, Halil, Işletmecilikte Fortran IV ile Programlama, A. Ü. Siyasal Bilgiler Fakültesi Yayını, 1988.

Sarıaslan, Halil, Sıra Bekleme Sistemlerinde Simulasyon Tekniği, A. Ü. Siyasal Bilgiler Fakültesi Yayını, 1989.

Sanaslan, Halil, Kaynak Dağılımında Doğrusal Programlama, Turhan Kitabevi, 1990.

Şen, Salim, Işletme Yönetimine Modeller Yoluyla Yaklaşım, AITIA, 1978. 